\title{
LEVANTAMENTO QUALI-QUANTITATIVO DA ARBORIZAÇÃO URBANA NA AVENIDA Marechal Rondon, SANTARÉm-PA
}

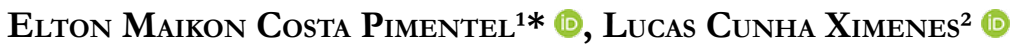

1 Universidade Federal do Oeste do Pará. Instituto de Biodiversidade e Florestas. Rua Vera Paž s/n (Unidade Tapajós), bairro Salé, Santarém, Pará, Brasil. CEP: 68040-400.

2 Universidade Federal do Oeste do Pará. Programa de Pós-Graduação em Sociedade, Natureza e Desenvolvimento. Rua Vera Paž, s/n (Unidade Tapajós), bairro Salé, Santarém, Pará, Brasil. CEP: 68040-400.

* Autor para correspondência: maikonbf@,hotmail.com

Recebido em 26 de março de 2020. Aceito em 27 de julho de 2020. Publicado em 31 de julho de 2020.

Resumo - A vegetação urbana passou a ser observada, principalmente, a partir dos vários benefícios que proporciona aos meios urbanos e pelo importante papel no restabelecimento da relação entre o homem e o meio natural. O objetivo deste estudo é realizar um levantamento quali-quantitativo da arborização na Avenida Marechal Rondon, localizada no município de Santarém - Pará, afim de se obter subsídios que possam servir de base na discussão e elaboração de um plano diretor de arborização urbana para este município. Com relação à metodologia, utilizou-se pesquisa bibliográfica e, o método de inventário utilizado foi de caráter quali-quantitativo, do tipo censo, também denominado inventário total. Foi amostrada uma população de 340 indivíduos, sendo que 68,8\% são de origem exótica. O indivíduo mais frequente foi a Mangifera indica, representando 42,1\% do total. Em torno de 75\% das árvores encontram-se sadias. O resultado alcançado com esta pesquisa foi que, no município em questão, há a necessidade da elaboração de um planejamento, que de acordo com escolhas técnicas de adequabilidade, possa chegar-se a um equilíbrio necessário e um monitoramento eficaz, de modo a obter-se o máximo dos benefícios da arborização urbana local.

Palavras-chave: Silvicultura Urbana; Vias Públicas; Inventário; Fitossanidade.

\section{Quali-quantitative survey of the urban afforestation at Marechal Rondon Avenue, Santarém, Pará}

Aвstract - The urban vegetation began to be observed, mainly, from the several benefits that it provides to the urban environment and by the important role in restoring the relation between man and nature. The objective of this study is to carry out a qualitative and quantitative survey of the afforestation on Marechal Rondon Avenue, located in the municipality of Santarém - Pará, in order to obtain subsidies that could serve as the basis for the discussion and elaboration of a master plan for urban afforestation in this municipality. Regarding the methodology, a bibliographic research was used, and the inventory method used was qualitative-quantitative, of the census type, also called total inventory. A population of 340 individuals was sampled, with $68.8 \%$ being of exotic origin. The most frequent individual was Mangifera indica, representing $42.1 \%$ of the total. About $75 \%$ of the trees are healthy. The result of this research demonstrated that, in the municipality in question, it is necessary to draw up a plan that, according to technical choices, can achieve a necessary balance and effective monitoring, in order to obtain the maximum benefit from local urban afforestation.

KeYwords: Urban Forestry; Public roads; Inventory; Plant health.

Encuesta cualitativa y cuantitativa de árboles urbanos en la Avenida Marechal Rondon, Santarém-PA

RESUMEN - Se ha comenzado a observar la vegetación urbana, principalmente, por los diversos beneficios que brinda a las áreas urbanas y por el importante papel en el restablecimiento de la relación entre el hombre y el medio ambiente natural. 
El objetivo de este estudio es llevar a cabo una encuesta cualitativa y cuantitativa de la forestación en la Avenida Marechal Rondon, ubicada en el municipio de Santarém - Pará, para obtener subsidios que puedan servir como base para la discusión y elaboración de un plan maestro de forestación urbana para este municipio. En cuanto a la metodología, se utilizó la investigación bibliográfica y el método de inventario utilizado fue de carácter cualitativo y cuantitativo, del tipo de censo, también llamado inventario total. Se tomaron muestras de una población de 340 individuos, de los cuales el 68.8\% son de origen exótico. El individuo más frecuente fue Mangifera indica, que representa el 42,1\% del total. Alrededor del 75\% de los árboles están sanos. El resultado logrado con esta investigación fue que, en el municipio en cuestión, existe la necesidad de elaborar una planificación que, de acuerdo con las opciones de adecuación técnica, pueda alcanzar el equilibrio necesario y un monitoreo efectivo, con el fin de obtener el máximo de los beneficios de la forestación urbana local.

Palabras clave: Silvicultura urbana; Caminos públicos; Inventario; Fitosanidad.

\section{INTRODUÇÃO}

Grande parte da população mundial vive nos centros urbanizados, necessitando cada vez mais, de condições que possibilitem uma melhoria na convivência das pessoas em um ambiente muitas vezes adverso (Gonçalves e Paiva 2004). Estudos da Organização das Nações Unidas (ONU 2012), apontam que até o ano 2030, aproximadamente $60 \%$ da população mundial viverá nos centros urbanos e que mais de $95 \%$ desse crescimento ocorrerá nos países em desenvolvimento. No Brasil, dados do Instituto Brasileiro de Geografia e Estatística (IBGE 2010) apontam que ao início da década corrente, mais de $80 \%$ da população vivia em áreas urbanas.

Um dos efeitos da urbanização acelerada que ocorreu no último século são as grandes modificações das paisagens (Gonçalves e Paiva 2004). Desta forma, com a expansão das áreas urbanas, o surgimento da luz elétrica e das redes de abastecimento de água, coleta de esgoto e das telecomunicações, trouxeram para o meio urbano um complexo sistema de fiações, cabos e galerias que ocupam, atualmente, grande parte do ar e do subsolo. Assim sendo, os postes e a grande quantidade de fios da rede aérea de energia, por exemplo, passaram a interferir de forma efetiva nos projetos de arborização urbana (Milano e Dalcin 2000). Estes projetos buscam evitar situações de conflito entre esses elementos urbanos e a arborização, com a implantação de espécies adequadas a cada situação (Rachid e Couto 1999; Silva Filho et al. 2002).

A vegetação urbana também passou a ser observada, principalmente, devido a vários benefícios que proporciona aos meios urbanos e pelo importante papel no restabelecimento da relação entre o homem e o meio natural (Gomes e Soares 2003). Isto beneficia a qualidade do ar com a fixação de gases tóxicos, além de amenizar o microclima local, reduz a velocidade do vento e realiza função ecológica e estética (Silva et al. 2007). Nesse contexto, a arborização urbana tornou-se um fator decisivo para proporcionar melhorias valiosas na qualidade de vida dos munícipes (Westphal 2000) e, como qualquer outro patrimônio público, requer investimento técnico/ financeiro e manutenção (Lima 2013).

Embora a arborização esteja presente em vários ambientes distintos da paisagem urbana, a via pública é o local mais comum de ser vista, seja nas calçadas ou nos canteiros centrais (Gonçalves e Paiva 2004), o que pode acarretar conflitos entre as árvores e outros elementos urbanos (Velasco 2003). A falta de planejamento dessa arborização é evidenciada em diversos municípios e capitais brasileiras, o que resulta em problemas como a diversidade reduzida de espécies (Silva et al. 2007; Melo et al. 2007) e o uso excessivo de espécies exóticas oriundas de outros biomas que nem sempre se adaptam ao ambiente urbano (Biondi e Leal 2008).

$\mathrm{O}$ uso de espécies inadequadas, a arborização irregular ou desapropriada para as vias urbanas e a falta de manutenção representam riscos para as pessoas e para o patrimônio (Rachid e Couto 1999). Por exemplo, árvores com raízes tabulares podem se espalhar pela superfície do solo, provocando rachaduras em calçadas, 
vias, muros e construções, acarretando assim, em prejuízos ao patrimônio físico urbano (Tempra 2007). Espécies que produzem flores ou frutos muito grandes, provocam maior sujeira na via, no caso das flores, e, no caso dos frutos grandes, podem provocar acidentes ou prejuízos ao se desprenderem das árvores (Silva Filho et al. 2002; Fernandes 2011). A inconsistência, ou inexistência, na realização das podas, por exemplo, pode resultar em prejuízos para rede de cabos aéreos (Milano e Dalcin 2000) ou, até mesmo, causar a queda de galhos sobre veículos, construções e passantes (Silva Filho et al. 2002).

Portanto, diante da complexidade do sistema de arborização urbana, torna-se necessária a efetivação do inventário da arborização, pois por meio dele, pode-se conhecer o patrimônio arbóreo e identificar as necessidades de manejo, bem como definir prioridades de intervenção (Melo et al. 2007). Além de embasar e direcionar as ações de planejamento ambiental, os inventários da arborização urbana devem ser realizados mediante um processo de amostragem apropriado ou censo arbóreo (Silva; Paiva; Gonçalves 2007; Bobrowski 2011), fornecendo, dessa forma, diferentes tipos de informações, além de possibilitar o cadastro espacial das árvores e de identificar deficiências ou falhas de plantio (Sanches; Costa; Silva Filho 2008; Araujo e Araujo 2016).

Os inventários para avaliação da arborização de ruas podem ser de caráter quantitativo, qualitativo ou quali-quantitativo (Melo; Filho; Rodolfo 2007). Entretanto, as análises por combinação quali-quantitativas são mais eficientes, pois permitem conhecer tanto a quantidade quanto a distribuição das árvores no meio urbano, juntamente com suas características de qualidade (Silva et al. 2007).

Diante do cenário exposto, este estudo tem como objetivo realizar um levantamento quali-quantitativo da arborização urbana na Avenida Marechal Rondon, localizada no município de Santarém - Pará, a fim de se obter subsídios que possam servir de base na discussão e elaboração de um plano diretor de arborização urbana para este município.

\section{Material e mÉtodos}

Área de estudo

O estudo foi desenvolvido no município de Santarém (Figura 1), localizado na região oeste do estado do Pará ( $02^{\circ} 26^{\prime} 35^{\prime}$ 'S e $54^{\circ} 42^{\prime} 30^{\prime}$ O O). É o principal centro urbano financeiro, comercial e cultural do oeste do estado. Ao longo do ano, a temperatura varia de $24^{\circ} \mathrm{C}$ a $33^{\circ} \mathrm{C}$ e é raramente inferior a $22^{\circ} \mathrm{C}$ ou superior a $35^{\circ} \mathrm{C}$. A estação de maior precipitação dura de 26 dezembro a 15 de junho e a estação mais seca vai de 15 de junho a 26 de dezembro, tendo o mês de abril com maior índice pluviométrico (Weatherspark 2018). A área de unidade territorial é de $17.898,389 \mathrm{~km}^{2}$ e sua população estimada está em 296.302 habitantes (IBGE 2019). 
Figura 1. Localização do município de Santarém, Pará

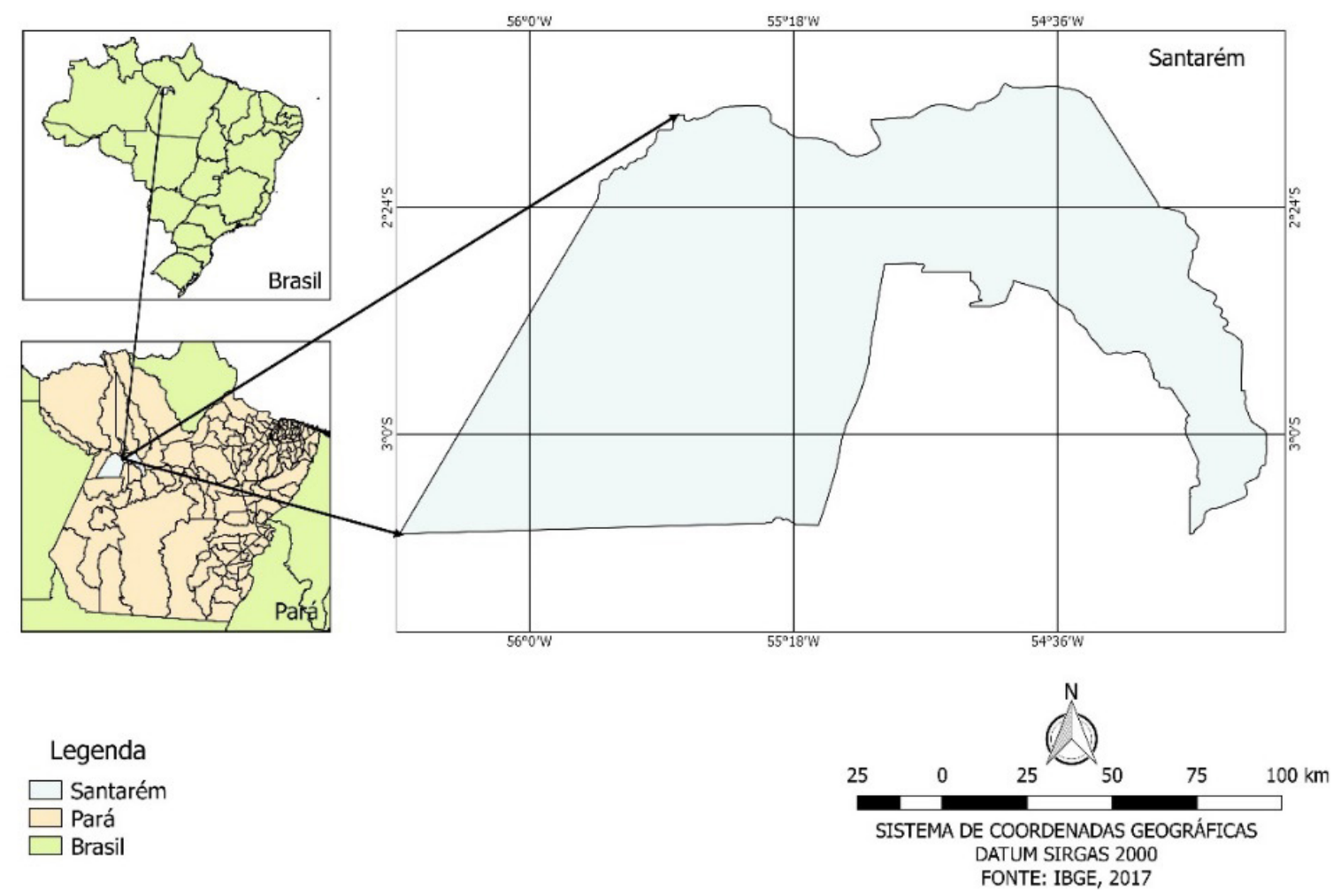

A via de estudo é um trecho da Avenida Marechal Rondon no perímetro entre a Rodovia Federal Santarém Cuiabá (BR - 163) até a Rodovia Estadual Curuá-Una (PA - 370) (Figura 2), na zona norte do município, totalizando aproximadamente 2950 metros dos 3650 metros que se encontram pavimentados. A avenida é importante para o fluxo de veículos e pedestres, com presença de canteiro central, edificações, sistema de distribuição de fiação elétrica e água.

Figura 2. Localização da Avenida Marechal Rondon, Santarém, Pará.

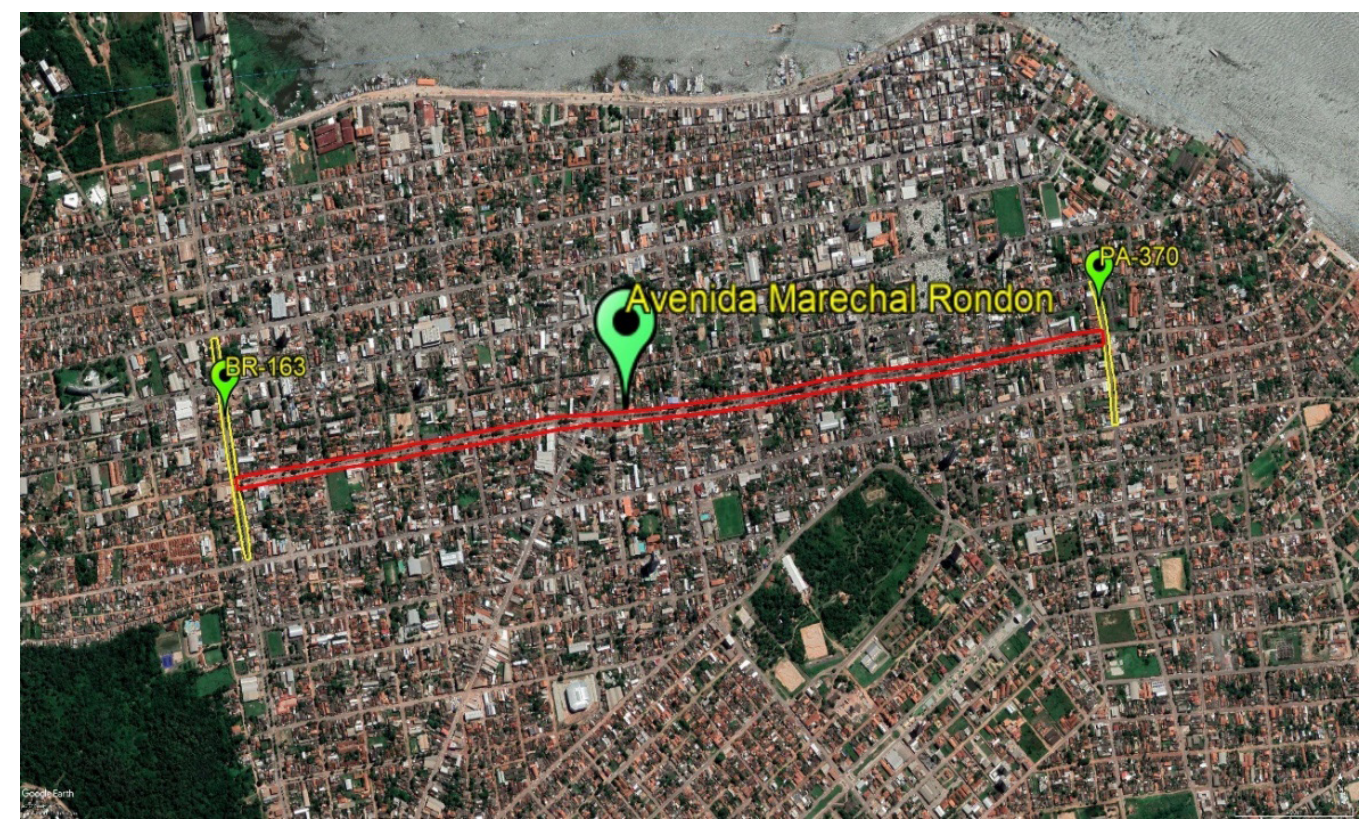

Fonte: Google Earth Pro 
O método de inventário utilizado no levantamento foi o de caráter quali-quantitativo, do tipo censo. Neste tipo de inventário, é realizada uma abordagem de 100\% dos indivíduos da população, sendo que a completa enumeração reproduz exatamente todas as características da população, ou seja, fornece os seus parâmetros reais (Péllico Netto e Brena 1997).

Os dados foram coletados no período de maio a junho de 2018 e o nível de inclusão pré-determinado foi a altura total superior a 2 metros. O inventário foi realizado com o auxílio de uma fita diamétrica para medir o Diâmetro a Altura do Peito (DAP) e uma trena de fibra de vidro de 30 metros para a obtenção do Diâmetro de Copa (DC). Uma ficha de campo específica adaptada de Silva et al. (2007), foi utilizada para as anotações das características analisadas, dividindo-se em parâmetros tanto qualitativos (Gil e Ximenes 2019) como quantitativos.

\section{Parâmetros qualitativos}

$\mathrm{Na}$ ficha de campo, foram coletadas as seguintes informações:

Espécie: Identificação das espécies, a partir da coleta e do conhecimento do nome vulgar, com o auxílio de um identificador botânico, posteriormente foi verificado o nome cientifico, a família botânica e a classificação das espécies quanto a sua origem, ou seja, se nativa ou exótica (Lorenzi 2003; Lorenzi 2016). A classificação taxonômica foi baseada no sistema APG III (2009) e a grafia dos nomes dos classificadores das espécies, bem como sua origem, foram consultadas na Lista de Espécies da Flora do Brasil (2016). Neste quesito, foram consideradas espécies exóticas aquelas que se inserem em áreas fora de seus limites naturais, sendo por dispersão acidental ou intencional (ONU 1992).

Posição da copa: Trata-se da posição das copas das árvores em relação às estruturas do espaço urbano, sendo classificada em: Sem interferência, quando a copa não interfere nas estruturas da via; Rua, quando a copa está atingindo a rua; e Residência, quando o crescimento da copa atinge as residências.

Sanidade da copa: Avaliação visual da aparência física da copa, podendo ser classificada como: Sadias, quando as copas das árvores apresentavam boas condições de saúde; Cupim, quando a copa apresentava ataque de cupins; Parasitas, quando esta apresentava a presença de parasitas (ervas daninhas); e Podridão, quando os galhos da copa demonstravam sinais de apodrecimento.

Posição do indivíduo: Referente à posição em que os indivíduos se encontravam na via, podendo ser: Canteiro central e Calçada.

Sanidade do fuste: aqui foram estabelecidas três classificações, avaliadas de forma visual: Sadio, quando o fuste apresentava boas condições de saúde; Cupim, quando o fuste se mostrava infestado por cupim; e Podridão, quando apresentava sinais de apodrecimento.

Posição da raiz: Neste quesito, as raízes das árvores inventariadas foram classificadas como: Sem afloramento, quando as raízes não apresentavam afloramento; Sem afloramento com rachadura, quando as raízes não apresentavam afloramento, porém haviam rachaduras nas calçadas e canteiro central; Afloramento contido, quando ocorre o afloramento das raízes sem causar danos estruturais; e Afloramento com rachadura, quando estas se apresentavam afloradas e causando rachaduras nas calçadas e no canteiro central.

Sanidade da raiz: Condições fitossanitárias das raízes, estabelecidas visualmente por quatro aspectos: Sem danos, quando as raízes se encontravam sem danos visíveis; Raiz cortada, quando estas se apresentavam com algum trauma antrópico; Apodrecimento, quando as raízes exibiam sinais de podridão; e Raiz estrangulada, quando estas mostravam sinais de estrangulamento, ocasionada pelas estruturas presentes na via. 
Fiação: Conflito entre a fiação elétrica e/ou de comunicação e as árvores. Esse parâmetro foi classificado em: Ausente, quando não havia conflito entre a fiação e os indivíduos arbóreos; Potencial, quando as árvores e a fiação estavam em potencial risco de conflito; e Presente, quando ocorria o conflito das copas com a fiação.

Manejo: avaliação da necessidade de manejo dos indivíduos arbóreos presentes na via, podendo ser classificada em: Ausente, quando não há necessidade de manejo; Poda, quando se detectou a necessidade de poda da planta; Substituição, quando o indivíduo arbóreo apresentou necessidade de ser substituído, devido a iminência significativa de queda; e Remoção, quando houve a necessidade de retirar em definitivo a árvore da via, se estiver causando danos comprovados ao patrimônio.

\section{Parâmetros quantitativos}

Diâmetro à altura do peito (DAP): medido à 1,30 $\mathrm{m}$ do solo, com o auxílio de uma fita diamétrica graduada. Diâmetro de copa (DC): utilizando uma trena métrica graduada, mediu-se a projeção da copa da árvore sobre o solo no sentido longitudinal e transversal à calçada, e ao tirar a média, obteve-se o diâmetro médio de copa (Silva et al. 2007).

Altura total: as árvores foram classificadas quanto ao seu porte, com a altura total estimada visualmente em metros, considerando a medida desde a base até o topo da copa do indivíduo. Árvores de pequeno porte: $\leq 5$ metros de altura. Médio porte: $>5$ e $\leq 10$ metros de altura. Grande porte: $>10$ metros. Adaptado de Biondi e Leal (2009).

Análise dos dados

Os dados registrados nas fichas de campo foram organizados em planilha eletrônica no Microsoft Office Excelß 2016 para o gerenciamento e análise das informações. Foi utilizada a estatística descritiva tanto para dados gerais quanto para as espécies de maior frequência presentes na via de forma separada.

\section{Resultados E Discussão}

\section{Levantamento arbóreo}

O levantamento realizado na Avenida Marechal Rondon encontrou 340 indivíduos divididos em 28 espécies, sendo 14 de espécies nativas e 14 de exóticas e com 68,8\% dos indivíduos exóticos e 31,2\% nativos (Tabela 1). As espécies mais frequentes foram: Mangifera indica L. (Mangueira), representando 42,1\% do total de indivíduos; seguida pelo Ficus benjamina L. (Fícus) com 9,1\%; Handroanthus serratifolius (Ipê Amarelo) e Azadirachta indica (Nim), com 7,94\% do total, cada; e Licania tomentosa (Oiti), com 7,64\% do total.

Embora o Brasil seja considerado um país com alta diversidade, com mais de 30 mil espécies nativas (Forzza et al. 2010), muitas cidades brasileiras priorizam o uso das espécies exóticas nos ambientes urbanos (Rocha et al. 2004; Santos et al. 2008, 2009; Barros et al. 2010), incluindo localidades na Amazônia brasileira (Vieira e Pagonopoulos 2020). Esta prática está relacionada, em grande parte, à herança colonial de paisagismo recebida pela maioria dos países tropicais (Ignatieva 2012).

De acordo com o levantamento, a Mangifera indica L. (Mangueira) foi a espécie com maior abundância, totalizando 143 indivíduos $(42,1 \%)$ de toda a arborização, representando quase o triplo do recomendado. O ideal para um bom equilíbrio da arborização urbana é que nenhuma espécie ultrapasse $15 \%$ do valor total de 
indivíduos. Por razões estéticas e fitossanitárias, a variedade de espécies e a proporção de uso de cada uma deve ser estabelecido em relação ao total de indivíduos a serem plantados (Milano e Dalcin 2000).

Dentre os exemplares exóticos, a espécie mais recorrente também foi a Mangifera indica L. (Mangueira), representando $61,1 \%$ do total.

Essas espécies podem ainda contribuir para a diminuição da extensão de mata nativa, uma vez que algumas delas podem ser "invasoras" e, ao serem disseminadas, invadem o espaço antes ocupado por espécies nativas (Biondi e Leal 2008).

Tabela 1. Espécies arbóreas que compõem a arborização urbana da avenida Marechal Rondon, Santarém, Pará.

\begin{tabular}{|c|c|c|c|}
\hline Nome Comum & Nome Científico & Origem & $\mathbf{N}^{\circ}$ indivíduos \\
\hline Acácia de Sião & Senna siamea (Lam.) H.S. Irwin \& Barneby & Exótica & 1 \\
\hline Alvineira & Andira parvifolia Mart. ex Benth & Nativa & 2 \\
\hline Ameixa-do-Pará & Eriobotrya japonica (Thunb.) Lindl. & Exótica & 2 \\
\hline Cajueiro & Anacardium occidentale $\mathrm{L}$. & Nativa & 14 \\
\hline Castanhola ou Chapéu-de-Sol & Terminalia catappa $\mathrm{L}$. & Exótica & 4 \\
\hline Cuieira & Crescentia cujete $\mathrm{L}$. & Exótica & 2 \\
\hline Eucalipto & Eucalyptus spp & Exótica & 1 \\
\hline Fícus & Ficus benjamina $\mathrm{L}$. & Exótica & 31 \\
\hline Goiabeira & Psidium guajava $\mathrm{L}$. & Nativa & 5 \\
\hline Ipê Amarelo & Handroanthus serratifolius (Vahl) S.O. Grose & Nativa & 27 \\
\hline Jambeiro & Sysygium malaccense (L.) Merr \& L.M. Perr & Exótica & 5 \\
\hline Lanterneira & Lophanthera lactescens Ducke & Nativa & 1 \\
\hline Limoeiro & Citrus limon (L.) Burm. f. & Exótica & 1 \\
\hline Mangueira & Mangifera indica $\mathrm{L}$. & Exótica & 143 \\
\hline Matafome Espinhenta & Pithecellobium diversifolium Benth. & Nativa & 8 \\
\hline Munguba & Pachira aquática Aubl. & Nativa & 1 \\
\hline Murici & Byrsonima sericea $\mathrm{DC}$. & Nativa & 1 \\
\hline $\mathrm{Nim}$ & Azadirachta indica A. Juss. & Exótica & 27 \\
\hline Noni & Morinda citrifolia $\mathrm{L}$. & Exótica & 2 \\
\hline Oiti & Licania tomentosa (Benth.) Fritsch & Nativa & 26 \\
\hline Palmeira Imperial & Roystonea oleraceae L.H. Bailey & Exótica & 4 \\
\hline Paricá & Scbizolobium amazonicum Huber ex Ducke & Nativa & 1 \\
\hline Pingo-de-Ouro & Duranta repens $\mathrm{L}$. & Nativa & 1 \\
\hline Peão Branco & Jatropha curcas L. & Nativa & 1 \\
\hline Sapupira & Andira inermis (W. Wright) Kunth ex DC & Nativa & 17 \\
\hline Tamarindo & Tamarindus indica $\mathrm{L}$. & Exótica & 7 \\
\hline Taperebá & Spondias mombin $\mathrm{L}$. & Nativa & 1 \\
\hline Tento Vermelho & Adenanthera pavonina $\mathrm{L}$. & Exótica & 4 \\
\hline Total de indivíduos & & & 340 \\
\hline
\end{tabular}


A Mangifera indica é um exemplo de espécie exótica predominante na região Norte do país e tornou-se símbolo histórico da mesma, adotada como árvore símbolo de várias cidades, dentre elas Belém, capital do Pará (Brito e Hossomi 2015). Esta espécie aparece em número elevado em outros levantamentos realizados em cidades da região norte, como em Macapá, no Amapá (Castro; Dias e Amanajás 2016) e em Belém, no Pará (Bessa et al. 2013). A média da frequência de Mangifera indica nesses levantamentos foi de 45,7\%. Neste estudo, a porcentagem desta espécie na arborização ficou em 42,1\% dos indivíduos observados, seguindo o mesmo padrão dos estudos realizados na Região Norte do país.

Mas apesar de sua ampla inserção na arborização, esta não é uma espécie adequada às vias públicas (Tempra 2007). Por ser de grande porte e produzir frutos graúdos, estes podem vir a causar danos a veículos, acidentes com pedestres e atrair insetos, como consequência da sujeira causada em calçadas e ruas com a queda de seus frutos (Morigi e Bovo 2013).

O Handroanthus serratifolius (Ipê Amarelo) foi a espécie nativa que mais ocorreu na avenida Marechal Rondon. Sabe-se que a inserção de espécies nativas nos projetos de arborização urbana contribui para a manutenção da biodiversidade e nos processos ecológicos, fornecendo valor cultural às cidades, além de agregar beleza às paisagens urbanas (Araujo e Araujo 2016). Portanto, o uso de espécies nativas de cada região no planejamento da arborização urbana deve ser promovido e incentivado cada vez mais pelos órgãos governamentais, universidades, ONGs (Organizações Não Governamentais) ambientais e até mesmo exigidos legalmente por legislação própria.

\section{Posição da copa, do indivíduo e da raǐ.}

Observou-se que 73\% dos indivíduos estudados foram descritos como: Sem interferência, portanto, suas copas não se encontravam projetadas para a rua ou residências. Logo, é importante atentar-se para os $27 \%$ das árvores que possuem suas copas projetadas para Rua e Residência, pois podem trazer problemas para veículos e pedestres.

Nas calçadas, as copas podem facilitar a ação de bandidos, dificultando a iluminação pública e também quando projetadas para as residências, facilita a ação de pessoas mal-intencionadas a pularem para o interior das casas e cometer delitos. Projetados para a rua, os galhos baixos podem interferir no trânsito de pedestres e veículos, obstruindo a visibilidade de placas de orientação (Ribeiro 2009).

Este tipo de problema pode ser tratado com a poda de levantamento, no qual são removidos os ramos mais baixos da copa que impedem a livre circulação de veículos e pessoas (Prefeitura de São Paulo 2015).

A pesquisa mostrou que 79\% das árvores estudadas encontram-se distribuídas no Canteiro central, e apenas 21\% na Calçada. Entre essas, a Mangifera indica representou 51\% da quantidade disposta no canteiro central da via. Sabe-se que os locais ideais para o plantio de árvores de grande porte, como a Mangifera indica, são em canteiros centrais de avenidas, praças, parques e quintais grandes (Fernandes 2011).

Em relação a isso, pode-se perceber que tais parâmetros foram parcialmente respeitados no plantio desta espécie na via, uma vez que 137 dos 143 indivíduos estão presentes no canteiro central.

Os exemplares de Mangifera indica em especial, são indivíduos de grande porte e as vias públicas nem sempre são largas o bastante para comportá-los ou não são devidamente planejadas para recebê-los, o que acarreta disputa de espaço (Fernandes 2011). Um ponto positivo na avenida pesquisada, é a pouca inserção dessa espécie nas calçadas, apenas 6 dos 143 indivíduos. Destes 6 indivíduos, apenas 1 possui porte médio, apresentando problemas de afloramento de raízes e rachaduras na calçada, sendo que nenhum deles apresenta disputa com a fiação ou causou danos estruturais a muros e construções.

Em relação aos danos provocados por raízes, entre os 340 indivíduos, apenas 4\% apresentaram Afloramento com Rachadura de calçada a sua volta, sendo eles, de 10 espécies distintas, não formando, neste caso, um padrão. 
O caso de Afloramento Contido foi apresentado por 52 indivíduos, ou $15 \%$ do total, sendo que, Mangifera indica, Ficus benjamina e Anacardium occidentales, juntos representam 67\% dos indivíduos com afloramento contido e todos categorizados como sendo de médio porte.

Apenas 10 indivíduos, ou 3\% do total, apresentaram rachaduras na calçada a sua volta, porém sem exposição das raízes, sendo 4 indivíduos de Licania tomentosa, 2 de Syasygium malaccense e 1 de Terminalia catappa, Pithecellobium diversifolium, Mangifera indica e Andira inermis.

Por fim, um total de 266 indivíduos, ou 78\%, não apresentaram nenhum tipo de afloramento, tendo em vista que a maioria das árvores se encontram no canteiro central. Patrício (2017), destaca que os impedimentos físicos presentes nas áreas de calçada, como solo coberto por concreto, proximidades a áreas concretadas podem causar exposição de raízes.

Resultado semelhante foi encontrado no estudo de Patricio (2017), em Cuiabá - MT, onde 79\% dos indivíduos estudados não apresentaram raízes expostas. $\mathrm{O}$ mesmo autor assegura ainda, que em solos expostos, onde não há concretagem, há melhores condições de formação das raízes sem exposição.

\section{Qualidade fitossanitária dos indivíduos}

Detectou-se que 74,7\% do total dos indivíduos estudados encontram-se "Sadios", ou seja, apresentam boas condições de saúde. Além disso, 32,5\% das espécies exóticas apresentaram algum problema fitossanitário e entre as nativas este número foi de apenas 4,7\%, evidenciando a importância da adaptação de espécies nativas na composição da arborização urbana, em se tratando de fitossanidade.

A utilização de espécies nativas é tecnicamente recomendada, a fim de garantir as relações ecológicas coevolutivas, genéticas e de dispersão de propágulos (pólen e sementes), envolvendo fauna e flora no ambiente urbano e também para a conservação de seu material genético autóctone (de Paiva et al. 2010).

Em relação à sanidade de copa, 80\% dos indivíduos analisados apresentaram-se como: Sadias, portanto, com boas condições de saúde. Cerca de 17\% dos indivíduos encontravam-se infectados por parasitas, 2\% sofriam com cupins e, apenas 1\% sofriam com algum tipo de podridão. Vale ressaltar que dos 56 indivíduos atacados por parasitas, $82 \%$ eram de Mangifera indica. Isto pode estar diretamente relacionado ao fato de que esta espécie é exótica no Brasil e que, por conta disso, está mais propensa ao ataque de parasitas (Fernandes 2011).

Em relação à sanidade de fuste, cerca de 7\% dos indivíduos encontravam-se infectados por cupins, apenas 1\% sofriam com algum tipo de podridão e, 92\% encontravam-se sadios.

A sanidade das raízes encontrava-se em ótimo estado, na quase totalidade dos indivíduos aparecendo o apodrecimento em apenas 1 indivíduo, uma Mangifera indica, que apresentava também, podridão de copa e fuste, além de conflito com demais componentes da via como rachaduras na calçada, fuste tomando toda a calçada e copa sobre a via.

Os resultados desses dois parâmetros mostraram-se satisfatórios e próximos aos encontrados por Melo et al. (2007), em Patos - PB, e por Santos et al. (2012) em Vitória da Conquista - BA, onde notou-se que 88,5\% e 91,6\%, respectivamente, das árvores encontravam-se em bom estado quanto à sanidade do fuste e raiz.

Fiação, Manejo e Altura total

Neste estudo, 20\% dos indivíduos arbóreos estudados apresentaram situações de conflito com a rede elétrica, sendo que 13\% apresentaram potencial para um conflito futuro com a rede devido ao seu crescimento e $67 \%$ Ausente. 
A Mangifera indica e o Ficus benjamina representam juntos 54\% dos conflitos existentes. Carvalho et al. 2013 indicam que o Ficus benjamina pode causar dados à elementos urbanos com destaque às fiações, por ser considerado de porte além do recomendado e de rápido crescimento. Os mesmos autores recomendam que sua plantação seja destinada a locais sem pavimentação e com espaço amplo, como praças e jardins.

Com relação ao manejo, 67\% das árvores inventariadas foram classificadas como: Ausente, ou seja, quando não houve necessidade da realização de qualquer tipo de manejo. Já 32\% dos indivíduos apresentaram necessidade de intervenção (Poda), e 1\% de remoção.

Esses resultados aproximam-se dos obtidos por Moraes e Machado (2014), em Timon-MA e de Junior et al. (2008) e no bairro Santa Rosa em Pombal-PB, onde 68\% das árvores estudadas não necessitavam de podas, nem conflitavam com a rede elétrica, respectivamente.

Periotto et al. (2016), afirmam que a relação conflitante entre redes elétricas e as árvores são comuns, uma vez que a arborização e os demais elementos da via disputam espaço e recursos para a sua manutenção. Nesse sentido, o mecanismo de poda, elaborado com critérios técnicos, torna-se uma eficiente ferramenta, aliado às escolhas apropriadas das espécies.

Além disso, é importante frisar que os indivíduos em Potencial (próximos à fiação) necessitam de monitoramento contínuo para evitar um futuro contato. Entre esses, a mangueira e o ipê amarelo, que representam 53,5\%. Castro (2016), propõe que para se ter um equilíbrio harmonioso entre arborização e sistema elétrico, é imprescindível que ocorra um planejamento por parte do poder público municipal e da concessionária de energia elétrica.

A necessidade de Remoção é relativamente baixa. Dentre os 340 indivíduos, apenas em 3 foi detectada a necessidade de serem retirados por apresentarem algum tipo de podridão. Primeiro caso, foi o Ficus benjamina apresentando podridão de fuste e afloramento de raízes com rachaduras da calçada. O segundo caso foi de Mangifera indica, apresentando posição de copa sobre a rua, fuste tomando toda a calçada e afloramento da raiz com rachaduras da calçada e podridão. E por último, mais um exemplar de Mangifera indica com podridão de copa, fuste e raízes, apresentando risco de tombamento eminente, no canteiro central.

Entretanto, vale ressaltar que a remoção de qualquer indivíduo arbóreo só poderá ser efetuada com prévia aprovação do órgão gestor ambiental do município, por meio de laudo expedido por profissional legalmente habilitado (Prefeitura de Santarém 2019).

Com relação à altura total, as árvores de pequeno porte representam $31 \%$ da totalidade estudada. As de porte médio constituem-se em 63\% e as de grande porte, apenas 6\%. Portanto, juntas, as árvores de pequeno e médio porte $(2$ a $10 \mathrm{~m}$ ) representam $94 \%$ da arborização. Esses números sugerem a existência de uma população arbórea ainda em desenvolvimento (Gonsalves 2017).

Em todos os estratos estabelecidos por este estudo, foram encontrados conflitos entre as árvores e a fiação elétrica, com destaque para os indivíduos de porte médio $(5 \mathrm{a} 10 \mathrm{~m})$ que representam $76 \%$ dos casos conflitantes. Diferente do que apresenta Dantas e Souza (2004), que as árvores de grande porte são as que, geralmente, têm contato com a rede elétrica.

No entanto, ressalta-se que o porte das espécies precisa estar adequadamente apropriado ao local de implantação, para que não haja custos demasiados com atividades de manejo, a fim de acomodá-las em lugares inadequados (Patricio 2017).

\section{Diâmetro à Altura do Peito e Diâmetro de Copa}

Sobre o diâmetro de copa (Figura 3), a concentração maior de árvores está no centro de classe 7,5, com 166 indivíduos. A mangueira, mais uma vez, acaba se destacando por representar 53\% do total de indivíduos. Esses dados reforçam o entendimento de que há uma arborização, em sua maioria, jovem e em desenvolvimento. 
Almeida (2009) destaca que as informações de diâmetro de copa, ainda que se tenha sofrido interferência por tratos silviculturais, são essenciais para o planejamento da arborização nas vias públicas. Silva, et al. (2007), por sua vez, ressaltam a importância de escolher espécies tentando prever, mesmo que de modo empírico, a variação no tamanho da copa quando em fase adulta.

Figura 3. Frequência de árvores em relação ao diâmetro de copa (DC), para os indivíduos inventariados na Avenida Marechal Rondon, Santarém-PA.

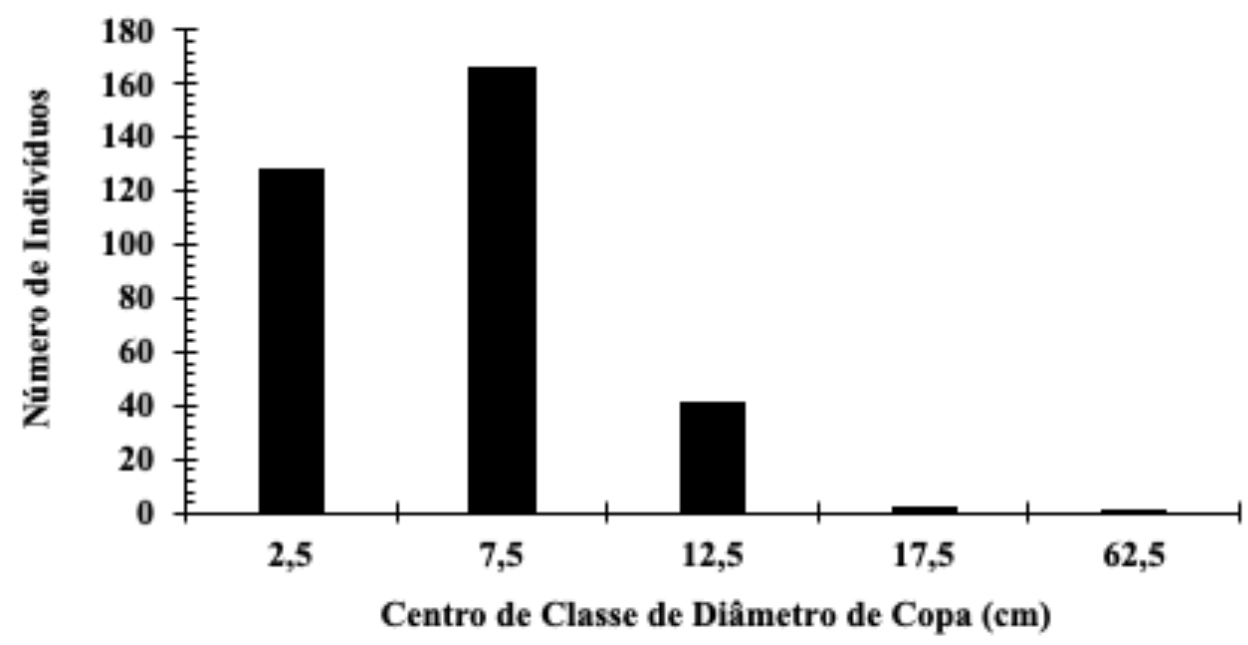

Em relação ao Diâmetro à altura do peito (Figura 4), a análise mostra uma predominância de árvores nos centros de classes entre $(5 \mathrm{~cm}$ e $25 \mathrm{~cm}$ ), onde encontra-se 70,9\% das árvores. Resultado que se aproxima dos obtidos por Fernandes et al. 2016, onde, nas mesmas classes, foram encontrados 79\% dos indivíduos estudados.

Figura 4. Frequência de árvores em relação ao diâmetro à altura do peito (DAP), para os indivíduos inventariados na Avenida Marechal Rondon, Santarém-PA.

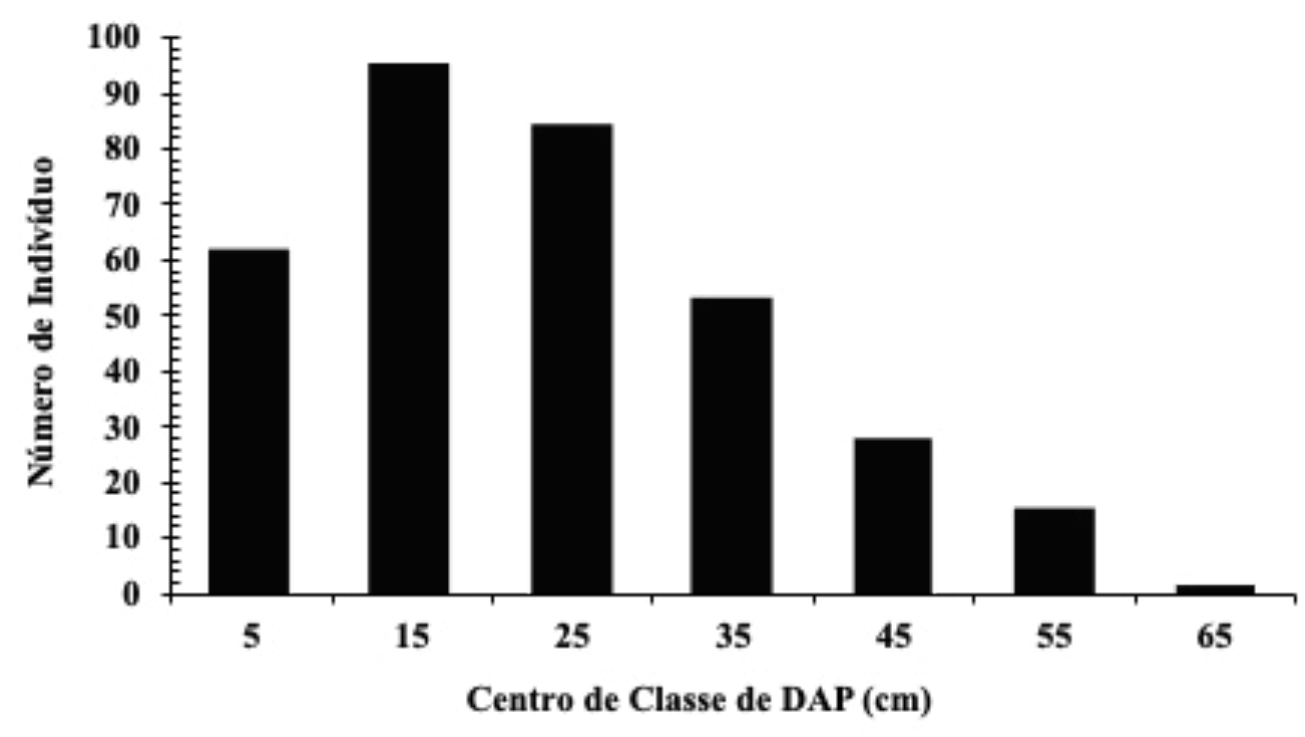

Pela distribuição dos indivíduos em classes diamétricas, nota-se uma tendência de redução no número de árvores com diâmetro maiores. E, assim como no estudo de Sousa et al. (2019), há uma grande proporção de indivíduos concentrados nas classes de menor diâmetro, indicando uma população arbórea em desenvolvimento (Costa, 2017). 


\section{CONCLUSÃo}

É possível notar um equilíbrio entre o número de espécies exóticas e nativas, porém há uma predominância de indivíduos arbóreos exóticos em função da quantidade de Mangifera indica na Avenida Marechal Rondon, o que não é recomendado pela literatura por desencadear perda na biodiversidade local e, como aponta este estudo, estarem propensas ao ataque de parasitas.

Além disso, no que concerne ao município e instituições afins, é importante incentivar o plantio de espécies nativas para a constituição da arborização urbana da avenida Marechal Rondon, visto que estas apresentam resultados fitossanitários melhores do que indivíduos de espécies exóticas.

Apesar de algumas incompatibilidades das espécies com as estruturas da avenida Marechal Rondon, a via em questão, encontra-se, no geral, em condições satisfatórias quanto aos aspectos avaliados. Vale ressaltar a importância da realização de podas de manutenção, a fim de evitar futuros conflitos com a rede elétrica. Entretanto há a necessidade de planejamento, que, de acordo com escolhas técnicas de adequabilidade, a partir de parcerias com órgãos públicos e universidades, possa chegar-se a um equilíbrio necessário e um monitoramento importante, de modo a obter-se os benefícios da arborização urbana.

\section{REFERÊNCIAS}

Almeida DND. 2009. Análise da Arborização Urbana de Cinco Cidades da Região Norte do Estado do Mato Grosso. Dissertação (Dissertação em Ciências Florestais e Ambientais) - UFMT. Cuiabá, p. 65.

APG III. 2009. An update of the Angiosperm Phylogeny Group classification for the orders and families of flowering plants: APG III. Botanical Journal of the Linnean Society, v. 2, p. 105-121.

Araujo ACB, Gracioli CR, Grimm EL, Longhi SJ. 2012. The assessment of floristic composition, size, health and current tree conservation of the International Park in Sant'ana do Livramento Brazil and Rivera Uruguay. Revista da Sociedade Brasileira de Arborização Urbana, 7: 66-74.

Araujo AJD, Araujo MND. 2016. Arborização Urbana. Série de Cadernos Técnicos da Agenda Parlamentar, Disponivel em: 〈https://www.crea-pr.org.br/ws/wp-content/uploads/2016/12/arborizacao-urbana.pdf〉. Acesso em: 28 mar. 2020.

Bessa MSC, Rodrigues RP, Santos CRC. 2013. Diagnóstico Qualitativo e Quantitativo de Arborização da Praça Batista Campos em Belém-PA. IV Congresso Brasileiro de Gestão Ambiental. IBEAS - Instituto Brasileiro de Estudos Ambiental. Salvador/BA - 25 a 28 novembro.

Biondi D, Leal L. 2008. Caracterização das plantas produzidas no Horto Municipal da Barreirinha, Curitiba/PR. Revista da Sociedade Brasileira de Arborização Urbana, 3:20-36.

Biondi D, Leal L. 2009. Avaliação de espécies plantadas experimentalmente na arborização de ruas da cidade de Curitiba - PR. Revista da Sociedade Brasileira de Arborização Urbana, 4:79-99.

Bobrowski R. 2011. Inventário florestal contínuo e dinâmica da arborização de ruas. In: Biondi D, Lima Neto EM. Pesquisa em arborização de ruas, 1:91-110.

Brito L, Hossomi ST. 2015. Espécies exóticas na arborização viária. ANAP. Periódico Técnico Científico Cidades Verdes, 03:69-74. 
Carvalho AAD, Silva LFD, Lima APD, Santos TP. 2013. A Inviabilidade do Ficus (Ficus Benjamina L.) para Arborização Viária. XIII Jornada de Ensino, Pesquisa e extensão - UFRPE. Recife, 09 a 13 Dezembeo.

Castro HSD, Dias TCADC, Amanajás VVV. 2016. As Geotecnologias como Ferramenta para o Diagnóstico da Arborização Urbana: o caso de Macapá, Amapá. Revista Ra’e Ga - O Espaço Geográfico em Análise, 38:146-168.

Costa CF, Fonseca RS, Almeida DCB, Oliveira MSD, Oliveira DDSO, Braga JRP. 2017. Espécies utilizadas na arborização em praças do município de Caxias, Maranhão. Revista da Sociedade Brasileira de Arborização Urbana, 12:65-78.

Dantas IC, Souza CMC. 2004. Arborização urbana na cidade de Campina Grande-PB. Inventário e suas espécies. Revista de Biologia e Ciências da Terra, 4 (2).

de Paiva AV, Lima ABM, Carvalho A, Junior AM, Gomes A, Melo CS, Farias CO, Reis C, Bezerra C, Junior EA, Macedo E, Lima ES, Sobrinho F, Silva FM, Bonfim JC, Junior LS, Correa M, Dumont ML, Junior MAI, Pantoja NV, Davila RM, Gabriel R, Silva RA, Cunha RM, Oliveira RS, Dias R, Nicheli SP, Costa S, Souza TC, Pereira TF, Castelo Z, Ferrari ZS. Inventário e diagnóstico da arborização urbana viária de Rio Branco, AC. Revista da Sociedade Brasileira de Arborização Urbana, 5: 144-159.

Fernandes B. 2011. Cartilha de Arborização Urbana. 3.ed. João Pessoa-Paraíba: SEMAM.

Fernandes LF, Betolino NR, Silva GRC, Miranda SDC. 2016. A vegetação lenhosa em quintais urbanos no município de Itapuranga-GO: composição florística e usos. Cultivando o Saber, 9(2):158-170.

Forzza RC, Baumgratz JFA, Bicudo CEM, Carvalho Júnior AA, Costa A, Costa DP, Hopkins M, Leitman PM, Lohmann LG, Maia LC, Martinelli G, Menezes M, Morim MP, Coelho MAN, Peixoto AL, Pirani JR, Prado J, Queiroz LP, Souza VC, Stehmann JR, Sylvestre LS, Walter BMT, Zappi D. 2010. Catálogo de plantas e fungos do Brasil. Rio de Janeiro: Andrea Jakobsson. Estúdio: Instituto de Pesquisa Jardim Botânico do Rio de Janeiro, v. 2, 828 p.

Gil WDS, Ximenes LC. 2019. Diagnóstico da Arborização Urbana da Avenida Presidente Vargas, Santarém-Pará. Eciclopédia Biosfera: 16: 1-15.

Gomes MAS, Soares BR. 2003. A Vegetação nos Centros Urbanos: Considerações Sobre os Espaços Verdes em Cidades médias Brasileiras. Estudos Geográficos, 1(1):19-29.

Gonçalves W, Paiva HN. 2004. Árvores para o ambiente urbano. Viçosa: Aprenda Fácil. Coleção Jardinagem e Paisagismo, 3:242 p.

Gonsalves ADM. 2017. Avaliação da Arborização Urbana do Bairro Santa Luzia, Itacoatiara, Amazonas. Universidade do Estado do Amazonas. Itacoatiara, p. 52.

IBGE - Instituto Brasileiro de Geografia e Estatística. 2010. Censo demográfico brasileiro. Disponível em:< http://7a12. ibge.gov.br/vamosconhecer-o-brasil/nosso-povo/caracteristicas-da-populacao>. Acesso em: 18/07/2018.

IBGE - Instituto Brasileiro de Geografia e Estatística. 2017. Mapas. Disponível em: https://mapas.ibge.gov.br/bases-e referenciais/bases-cartograficas/malhas-digitais. Acesso em Dezembro de 2018.

IBGE. Instituto Brasileiro de Geografia e Estatística. 2019. Brasil/Pará/Santarém. Disponivel em: <https://cidades.ibge. gov.br/brasil/pa/santarem/panorama>. Acesso em: 17 jan. 2019. 
Ignatieva M. 2012. Plant material for urban landscapes in the era of globalization: roots, challenges and innovative solutions. In: Richter, M., Weiland, U. (Eds.), Applied Urban Ecology: A Global Framework. Oxford: Wiley-Blackwell, p. $139-151$.

Junior FR, Melo RRD, Cunha TAD, Stangerlin DM. 2008. Análise da Arborização Urbana em Bairros da Cidade de Pombal no Estado da Paraíba. Revista da Sociedade Brasileira de Arborização Urbana, 3(4):3-19.

Lima DCA. 2013. Inventário das Espécies Arbóreas Utilizadas na Arborização das Praças de Manaus/AM. Universidade Federal do Amazonas. Manaus, p. 41.

Lista de Espécies da Flora do Brasil. 2016. Jardim Botânico do Rio de Janeiro. Disponível em: http://floradobrasil.jbrj. gov.br/reflora/PrincipalUC/PrincipalUC.do. Acesso em: 07 julho 2020.

Lorenzi H. 2003. Árvores Exóticas no Brasil: Madeiras, ornamentais e aromáticas. Nova Odessa: Instituto Plantarum. 368 p.

Lorenzi H. 2016. Árvores Brasileiras: manual de identificação e cultivo de planta arbórea nativas do Brasil. Nova Odessa: Instituto Plantarum. 3(6).

Melo RR, Filho JADL, Rodolfo Júnior F. 2007. Diagnóstico qualitativo e quantitativo da arborização urbana no bairro Bivar Olinto, Patos, Paraíba. Revista da Sociedade Brasileira de Arborização Urbana, 2(1):64-78.

Milano MS, Dalcin EC. 2000. Arborização de vias públicas. Rio de Janeiro: Light. 226 p.

Moraes LA, Machado RRB. 2014. Arborização Urbana no Município de Timon-MA: Inventário, Diversidade, e Diagnóstico Quali-quantitativo. Revista da Sociedade Brasileira de Arborização Urbana, 9(4):80-98.

Morigi JDB, Bovo MC. 2013. A qualidade do Ambiente Urbano: Uma breve reflexão sobre a ocorrência de espécies frutíferas na arborização das vias públicas do centro urbano de Mamborê (PR). II Simpósio de Estudos Urbanos: A dinâmica das cidades e a produção de espaço, Campo Mourão, 19 a 21 Agosto.

ONU - Organização das Nações Unidas. 2012. O futuro que queremos. Disponível em: <http://www.onu.org.br/rio20/ img/2012/01/OFuturoqueQueremos_rascunho_zero.pdf Acesso em: 20/07/2018.

ONU - Organização das Nações Unidas. 1992. Instituto de Recursos Mundiais; União Mundial para a Natureza; Programa das Nações Unidas para o Meio Ambiente. A estratégia global da biodiversidade - diretrizes de ação para estudar, salvar e usar de maneira sustentável e justa a riqueza biótica da Terra. Curitiba: World Resources Institute / Fund. O Boticário de Proteção à Natureza, 232 p.

Patricio PPM. 2017. Florística e Diagnóstico da Arborização da Universidade Federal de Mato Grosso, campus Cuiabá. (Dissertação em Ciências Florestais e Ambientais) UFMT - Cuiabá, p. 106.

Péllico Netto S, Brena DA. 1997. Inventário Florestal, v.1. Universidade Federal do Paraná. p. 316.

Periotto F, Pituco MM, Helmann AC, Santos TOD, Bortolotti SL. 2016. Análise da arborização urbana no município de Medianeira, Paraná. Revista da Sociedade Brasileira de Arborização Urbana, 11(2):59-74.

Prefeitura de São Paulo. 2015. Manual Técnico de Arborização Urbana. Disponivel em: <https://www.sosma.org.br/ wp-content/uploads/2015/03/MANUAL-ARBORIZACAO_22-01-15_.pdf>. Acesso em: 08 abr. 2019. 
Prefeitura de Santarém. 2019. Agência Santarém. Serviço de Poda e Corte de Árvores em Santarém. Disponivel em: <http://www.agenciasantarem.com.br/noticia/3463/>. Acesso em: 21/05/2019 Maio 2019.

Rachid C, Couto HTZD. 1999. Estudo da eficiência de dois métodos de amostragem de árvores de rua na cidade de São Carlos - SP. Scientia Forestalis, (56):59-68.

Ribeiro FABS. 2009. Arborização Urbana em Uberlândia: Percepção da População. Revista da Católica, 1(1):224-237.

Rocha RT, Leles PSDS, Oliveira Neto SN. 2004. Arborização de vias públicas em Nova Iguaçu, RJ: o caso dos bairros Rancho Novo e Centro. Revista Árvore, 28: 599-607.

Sanches PM, Costa JA, Silva Filho DF. 2008. Análise comparativa dos planos diretores de arborização enquanto instrumento de planejamento e gestão. Revista da Sociedade Brasileira de Arborização Urbana, 3(4):53-74.

Santos AAD, Maciel CMS, Barreto AMR, Paula AD, Paula EDCALD. 2012. Diagnóstico da Arborização Urbana da Avenida Olívia Flores, Vitória da Conquista - BA. Enciclopédia Biosfera, 8(14):1155-2012.

Santos AR, Rocha CFD, Bergallo HG. 2009. Native and exotic species in the urban landscape of the city of Rio de Janeiro, Brazil: density, richness, and arboreal deficit. Urban Ecosystems, 13: 209-222.

Santos AR, Bergallo HDG, Rocha CFD. 2008. Paisagem urbana alienígena. Ciência Hoje, 41: 68-73.

Silva AG, Paiva HN, Gonçalves W. 2007.Avaliando a arborização urbana. 1. Ed. Viçosa - MG: Aprenda Fácil, 5:296

Silva Filho DFD, Pizetta PCU, Almeida JBSAD, Pivetta KFL, Ferraudo AS. 2002. Banco de Dados Relacional Para Cadastro, Avaliaзго е Manejo da Arborizaзго еm Vias Pъblicas. Revista. Árvore, 26(5):629-642.

Sousa RRD, Araújo LHBD, Borges CHA, Souto PC, Souto JS. 2019. Diagnóstico da Arborização do Campus de Patos - PB. BIOFIX Scientific Journal, 4(1):43-51.

Tempra NB. 2007. A mangueira como elemento de arborização urbana. ECODebate. Disponível em: https://www. ecodebate.com.br/2007/11/13/a-mangueira-como-elemento-de-arborizacao-urbana-por-nelson-batista-tembra/ Acesso em: set./2018.

Velasco GN. 2003. Arborização Viária x Sistema de Distribuição de Energia Elétrica: Avaliação dos Custos, Estudos das Podas e Levantamento de Problemas Fitotécnico. 94 f. Dissertação (Dissertação em Agronomia). ESALQ. São Paulo, p. 117.

Vieira TA, Panagopoulos T. 2020. Urban Forestry in Brazilian Amazonia. Sustainability, 12: 1-19.

Weatherspark. 2018. Condições meteorológicas médias de Santarém Brasil. WEATHERSPARK. Disponivel em: <https:// pt.weatherspark.com/countries/BR/16/1506807>. Acesso em: 14 ago. 2018.

Westphal MF. 2000. O Movimento Cidades/Municípios Saudáveis: um compromisso com a qualidade de vida. Ciência e saúde coletiva, 5(1):39-51. 